\title{
Erratum to: Appraisal of Drought Characteristics of Representative Drought Indices using Meteorological Variables
}

\author{
Junehyeong Park*, Yoon-Jin Lim**, Baek-Jo Kim***, and Jang Hyun Sung**** \\ Received October 25, 2016/Revised May 29, 2017/Accepted May 30, 2017/Published Online September 29, 2017
}

Erratum to: KSCE Journal of Civil Engineering (2018) 22(5):2002-2009

DOI 10.1007/s12205-017-1744-x

This erratum is published to notice an error in title of figure.

Errata:

The original title of Fig. 2 was:

Fig. 1. Location of KMA ASOS 60 Weather Stations of South Korea

Was altered as:

Fig. 2. Annual Averaged Precipitation (left) and Potential Evapotranspiration (right) of $1973 \sim 2015$ for 60 ASOS Weather Stations.

The original article has been corrected.

\footnotetext{
*Member, Researcher, Earth System Research Division, National Institute of Meteorological Science, Jeju 63568, Korea (E-mail: sai0259@gmail.com) **Senior Researcher, Earth System Research Division, National Institute of Meteorological Science, Jeju 63568, Korea (E-mail: yoonjin.lim@korea.kr) ***Director, Applied Meteorology Research Division, National Institute of Meteorological Science, Jeju 63568, Korea (E-mail: bjkim@kma.go.kr)

****Member, Researcher, Ministry of Land, Infrastructure and Transport, Han River Flood Control Office, Seoul 06501, Korea (Corresponding Author, Email: jhsung1@korea.kr) 